\title{
Higher education teachers' experiences of becoming research active: striving for university status in the Global South
}

\author{
Joanna Joseph Jeyaraj ${ }^{1}$ D $\cdot$ Navé Wald $^{2} \cdot$ Tony Harland $^{2}$
}

Received: 25 December 2020 / Revised: 10 March 2021 / Accepted: 24 March 2021 / Published online: 5 April 2021

(c) Education Research Institute, Seoul National University, Seoul, Korea 2021

\begin{abstract}
Higher education institutions are seen as pivotal for fostering national economic growth in a globalised knowledge economy. Conducting research is an important aspect of that role, and there is pressure on institutions to increase their knowledge production, as well as to offer advanced research degrees. This requires academics with doctoral level qualification who research in their field. Research productivity is important for institutions because it contributes to prestige and better rankings in league tables, which result in more or better resources. This qualitative study examines the notion of 'turning teachers into academics' through the experiences of lecturers in a teaching-focused institution in Malaysia seeking university status. Becoming research active requires resources and a supportive environment that were largely unavailable, and so participants experienced an unhealthy intensification of their academic work and struggled to do research or complete their $\mathrm{PhD}$ qualifications. The study showed that a successful transition required teachers to be genuinely motivated to do research and the institutions to provide adequate support. Under current circumstances of fierce competition between institutions and the inability to compromise teaching allocations, it is not clear how, or if, such a transition can happen without adversely affecting staff wellbeing.
\end{abstract}

Keywords Teaching-focused $\cdot$ Research-active $\cdot$ University ranking $\cdot$ Work intensification $\cdot$ New higher education institutions

\section{Introduction}

In this paper, we present a case study that explores the experiences of a group of staff during a period when their ambitious private sector university college in Malaysia was seeking full university status. The change from being teacher-focused entailed responding to a national agenda for research excellence and developing as a research-led institution. The questions that concerned us were about how teachers were managing to make the transition to becoming research active and what supported or hindered them on their journey. We argue that these are important issues in the current changing context of higher education globally.

Joanna Joseph Jeyaraj

joannajoseph@upm.edu.my

1 Faculty of Educational Studies, Universiti Putra Malaysia, Seri Kembangan, Jalan Universiti 1 Serdang, 43400 Selangor, Malaysia

2 Higher Education Development Centre, University of Otago, 65/75 Union Place West, Dunedin 9016, New Zealand
The positioning of the knowledge economy as a main driver of national economic growth in an increasingly globalised and competitive world has directed much attention to the role of the higher education sector in this environment. Research and innovation are at the centre of such an economy, and developing a workforce with the necessary skills has been a priority. In many countries, higher education institutions have had to offer higher-level programmes and increase their own research capacity and capability. Research-intensive universities are already well positioned for fulfilling these roles, but other institutions, such as those dedicated to vocational training, have focused on teaching and many have had to transform themselves in order to become more research active to better contribute to national economic development (Hazelkorn \& Moynihan, 2010).

At the same time, over the last few decades the higher education sector has experienced political, economic and demographic changes that have led to dwindling funding and applicant pools and intensified competition between institutions (O'Meara, 2007). Nothing has epitomised this competition more than the focus on improving one's position 
in ranking exercises (Hazelkorn, 2015; Pusser \& Marginson, 2013). While rankings may not reflect the quality of the student experience, they do affect the quantity and quality of enrolled students and thus income and prestige (O'Meara, 2007):

... institutions strive for prestige as they do other resources. With prestige comes more resources, which help the institution gain more prestige, which brings more resources and on and on. While institutions have sought many types of prestige over time, currently the coin of the realm for many institutions seems to be college rankings and classifications.

(O’Meara, 2007, p. 129)

O'Meara (2007) has conceptualised the pursuit of prestige and associated higher-ranking with the idea of 'striving'. Additional characteristics of this phenomenon include reallocation of resources away from teaching towards research and administration, a shift in emphasis from undergraduate to postgraduate programmes, and staff recruitment with a research emphasis.

The global fascination with rankings and the aspiration to improve one's position have been entangled with the increased importance bestowed on research and knowledge production. Therefore, the phenomenon whereby teachingfocused institutions have transitioned-following external as well as internal pressure-into becoming research active has been important across the world. Seeking to become a university and striving for higher status has many positive outcomes for an institution and its staff. The obvious benefits are economic with implications for recruitment of local and international students and a higher fees structure. In turn, and over time, this leads to a change in the working conditions and status of academic staff. Such shifts gained pace in the Global North from the 1980s and in more recent years this has included the Global South. Many of these institutions did not have university status and were previously known variously as polytechnics, institutes of technology and colleges (of education, community, liberal arts) or university colleges (Hazelkorn, 2005, 2008; Kyvik \& Lepori, 2010; O'Meara, 2007; O'Meara \& Bloomgarden, 2011). In the European context, Hazelkorn (2008) has referred to them collectively as 'new higher education institutions' (new HEIs).

Research-intensive universities are important to developing and middle-income countries as they offer social and economic progress (Altbach, 2009). However, at present the international literature on striving for university status focuses predominantly on the Global North, especially in Europe and the US. These include nations that often enjoy a relative high status for their higher education sectors and therefore are better positioned to succeed in realising their aspirations, at least in international rankings. The literature that examines the transition between being teaching-focused to research-active, thus, is often rooted in this context. Stensaker et al. (2019, p. 540) note that 'Much less attention has been given to institutions and nations occupying less favourable rankings in the race for reputation and international standing.' We share this sentiment and seek to broaden the scope of research to include institutions and higher education sectors of lower status where we can identify different patterns and challenges.

The transition of new HEIs into being research active and then competing on a global stage entails numerous challenges. At the national level, there are issues of legal frameworks regarding the operations of new HEIs and funding priorities towards research output. At the institutional level, challenges have been identified around developing adequate policies, resources and a supportive environment and culture. At a personal level, teachers need to transform into researchers. These challenges have been conceptualised by Kyvik and Lepori (2010) who suggest that the paradigm shifts required to create sustainable research involve institutional ambition, the individual to develop new practices, and for the institution and individual to respond to national and global developments in higher education. Based on these ideas, we have developed a framework that captures the relationship between the different forces that shape higher education, motivations for change, and academic work (Fig. 1).

The challenge for the study institution is first acquire a university designation, and then develop and sustain a culture of research excellence. The Malaysian higher education sector has approached this process by inviting institutions to apply for university status and because the government sets the criteria for this process, it gives clear direction for what is needed (Ministry of Education Malaysia, 2015; Tham, 2013). This strategic shift for non-university higher education institutions, and in particular those in the private sector (PHEIs), has been promoted by government and in order to gain university status, certain requirements relating to operation, finance, curriculum, quality, faculty, governance,

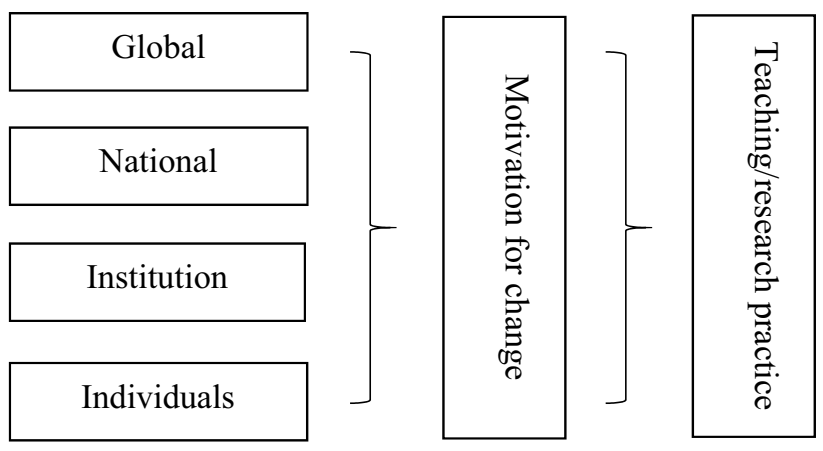

Fig. 1 A multi-scalar model of factors influencing the establishment of a research environment in a teaching-focused institution 
research and development, infrastructure and students must be met. Those institutions seeking to become a university must also respond to the Malaysian government's current National Education Strategic Plan and Economic Transformation Programme (Ministry of Education Malaysia, 2015). Each has similar goals of achieving a 'high income country' with 'developed nation status' (p. 6). Such status is globally determined and the target of financial improvement is focused mainly on economic prosperity, rather than any of the other purposes that a higher education might serve. Nevertheless, the means to achieve these two main goals are a highly-educated workforce, innovative research and global collaboration.

The application approach to becoming a university ensures a minimum level of research productivity on entry. At the same time there is no evidence to suggest this will result in producing a comparable research culture to the long-established research-intensive universities, either nationally or worldwide. For example, in 1992, the UK created a unitary university system and the polytechnics were given university status. Although developing quality research was seen as a long-term intergenerational project, a study of league tables and ranking showed that after more than 20 years, the majority of these new universities had not managed to compete with the older established institutions (Boliver, 2015).

In particular, the standards for research-intensiveness and research quality create a real burden for those academics (who are primarily teachers) as they change practice and develop new skills. It is here that the main challenges lie. Adapting to the new environment is known to be difficult (Hazelkorn, 2008; Hazelkorn \& Moynihan, 2010; Kyvik \& Lepori, 2010) and research has shown personal impacts on individuals, including issues around identity development, change or loss (Dugas et al., 2020; Garratt \& HammersleyFletcher, 2009; van Winkel et al., 2018), work-life balance (Gonzales et al., 2014), and an intensified work environment (Gonzales, 2015; Gonzales, et al., 2014; Martinez, 2019). Teacher attitudes towards research in newly established HEIs or those seeking university status are currently poorly understood but are known to vary considerably, from those hostile to the idea, to those who recognise its importance but struggle to adapt, to those who have embraced it and actively work to build a research profile (Hazelkorn, 2008).

Many teachers need to start the research journey by acquiring a $\mathrm{PhD}$ for their own research training and to become doctoral supervisors. In Malaysia there are strategies at both national and institutional levels to dramatically increase the number of $\mathrm{PhD}$ students (Ministry of Education Malaysia, 2015). New HEIs have to offer postgraduate courses and supervise $\mathrm{PhD}$ students, all of which require suitably qualified staff (Shariffuddin and Razali, 2017). It is generally accepted that 'Doctoral education lies at the core of a university's research capacity, and is also seen as the primary source of research productivity and innovation in the global knowledge economy' (Nerad et al., 2008, p. 3 ). Therefore, the $\mathrm{PhD}$ has both symbolic and material significance. At the individual level, the relationship between having a doctorate and becoming an active researcher after graduation is complex and not adequately understood; however, those who get a $\mathrm{PhD}$ do tend to enjoy better employment opportunities (Sinclair et al., 2014). While having a $\mathrm{PhD}$ does not guarantee a positive attitude towards conducting research, there should at least be a new appreciation of what research entails.

Attitudes towards research in new HEIs, where many staff do not have a doctorate, vary considerably, from those hostile to the idea, to those who recognise its importance but struggle to adapt, to those who have embraced it and actively work to build a research profile. Yet, it is widely accepted that having a research profile is an effective strategy for advancing one's career, as there are tangible rewards for those who secure external research funding and excel in publishing. Attaining such a research status also means being competitive for a position in a research-intensive university, where financial and status rewards are often greater (Hazelkorn, 2008). Striving at all levels, therefore, hinges on increasing the shares of doctorate holders, in HEIs and in society more broadly.

The Malaysian case-study under examination was conducted in a private university college that was established in 1969. Private higher education institutions (PHEIs), which provide Malaysians with greater access to education, have experienced remarkable growth and in 2019 there were 446 PHEIs, including universities, branch campuses, university colleges and colleges. The Ministry of Higher Education's commitment to grow PHEIs is reflected in its 2011-2015 action plan to upgrade institutions from colleges to both university colleges and universities, to encourage the establishment of elite private institutions with world-class standards, and to expand research and development in these institutions (Tham, 2013). In order to gain university status, certain requirements relating to operation, finance, curriculum, quality, faculty, governance, research and development, infrastructure, students and track record must be met.

The qualifications of staff members are an important requirement in this exercise. In 2015, 37 per cent of academics in public universities had a doctorate-level degree, with an equivalent rate of 13 per cent in private universities, university colleges and colleges (Ministry of Education Malaysia, 2015). These average figures do not reflect the diversity of institutions in the latter group; but nevertheless, university status requires a minimum of 20 per cent of academics to hold a $\mathrm{PhD}$ (and a maximum of $80 \%$ a Masters) (Shariffuddin \& Razali, 2017). So, for many, the ambitious project of 'turning teachers into academics' 
(Macfarlane \& Hughes, 2009, p. 7) has to start with a PhD. Yet in Malaysia, teaching staff not only have to attain PhDs and then train and work as researchers, but also attract grant income, publish in local and international highranked journals, present work at conferences and supervise doctoral students. All these tasks are routine for an established research-intensive university and so the playing field is not level across the sector, but neither is it level within an institution. For example, researchers are not evenly supported in the same way in different disciplines and STEM subject research is typically priority funded, attracts more $\mathrm{PhD}$ students and is more collaborative in nature than, say, humanities work. These differences create added complexity for those managing the research transition in a new HEI, and for those having to change to meet management demands and what is expected of them internationally.

To spur institutional excellence and to strengthen the role of both public and private institutions across the sector, rigorous assessment mechanisms with performance and outcome-based criteria have been put in place by the government. These include, the Rating System for Malaysian Higher Education Institutions (or its Malay acronym SETARA), which rates teaching, research and service, and the Malaysian Research Assessment Instrument (MyRA), which assesses research capabilities at an institutional level. MyRA has a list of assessment criteria that include, among others, the quantity and quality of researchers; quantity and quality of research; quantity and quality of postgraduates; and networking and linkages. Institutions receive a rating (6 stars being the highest) after they are assessed on areas such as the number of academic staff involved as principal researchers, the total amount of grants obtained, the total number of staff with a PhD or professional qualifications and the total number of publications in SCOPUS/WOS/ERA indexed journals.

Institutions that receive excellent ratings in these assessments become the institutions of choice for students both locally and internationally, and a considerable amount of institutional prestige is also gained. Such institutions become known as producers of high-quality research and of employable graduates. With academic status and prestige come more resources, which then go on to help institutions attain higher levels of prestige. As a proxy for prestige many institutions seem to focus on rankings (O'Meara, 2007) and it is this measure that the university college in this case study was concerned with when it was upgraded from a college to a university college in 2013, and at present it continues to strive towards achieving university status in the near future. Achieving that has ramifications for staff members, who get to be measured against a new set of standards, especially pertaining to research and postgraduate student supervision.

\section{The study}

This Malaysian case-study focuses on a private teachingfocused university college seeking university status. The study examined staff experiences of moving from being teaching-focused to developing the new and required standards for university level research. A purposive sampling approach was employed and call for participation was done through research networks within the institution, word of mouth and personal referrals. Participants who expressed interest were given an information sheet, interview protocol and consent form. Eighteen teachers took part, representing 10 subjects. Seven had a doctorate, nine were pursuing a doctorate and two with a master's degree were considering a doctorate.

Data were collected through semi-structured exploratory interviews that sought to understand how participants were experiencing the transition towards becoming more research active. Participants were asked about their conceptions of academic work, the challenges they faced in becoming more research active and writing for publication, and the support and strategies they sought and employed for overcoming those challenges. Interviews lasted between 45 and $90 \mathrm{~min}$. Data also included followup email correspondence when further clarification was needed and field notes made by the lead author. A general inductive approach was used for analysis which produced significant themes from the raw data (Thomas, 2006). Data collection and analysis was done by the first author, with the second and third authors checking to ensure the trustworthiness of the analysis and findings. Appropriate quotations that convey the core ideas of each theme are used with the participant's pseudonym (Table 1).

\section{Results and discussion}

The study institution had delivered a clear message for staff that it wanted to attain full university status, to create a new and sustained research culture and strive for greater prestige. In doing so, the institution would be responding to the national economic imperative of increasing research output and the number of PhD students. It had not gone for a strategy of requiring all academics to become research active but had adopted a more flexible approach for selective faculty change, mainly driven by HR policies and new recruitment goals. Although this approach may be seen as more agreeable (Hazelkorn, 2008), it nevertheless created pressure on individuals who wanted to remain as teachers and for those wishing to make the transition to researchers. Staff now saw different career paths that favoured 
Table 1 Participants main area of teaching and their $\mathrm{PhD}$ status

\begin{tabular}{|c|c|c|c|c|}
\hline \multirow[t]{2}{*}{ Pseudonym } & \multirow[t]{2}{*}{ Area of teaching } & \multicolumn{3}{|c|}{$\mathrm{PhD}$ status } \\
\hline & & Attained & Studying & Intending \\
\hline Amy & $\begin{array}{l}\text { English Language } \\
\text { Studies }\end{array}$ & & & $\mathrm{x}$ \\
\hline Charice & Education/ Translation & $\mathrm{x}$ & & \\
\hline Fay & $\begin{array}{l}\text { English Language } \\
\text { Studies }\end{array}$ & & & $\mathrm{x}$ \\
\hline Goh & Literature & & $\mathrm{x}$ & \\
\hline Harvey & $\begin{array}{l}\text { English Language } \\
\text { Studies }\end{array}$ & $\mathrm{x}$ & & \\
\hline Hayati & Education & $\mathrm{x}$ & & \\
\hline Ivan & Education & & $\mathrm{x}$ & \\
\hline Jennie & Literature & $\mathrm{x}$ & & \\
\hline Julie & Science Education & $\mathrm{x}$ & & \\
\hline Kamila & Psychology & & $\mathrm{x}$ & \\
\hline Kamini & Psychology & & $\mathrm{x}$ & \\
\hline $\mathrm{KiKi}$ & Graphic design & & $\mathrm{x}$ & \\
\hline Laila & Engineering & & $\mathrm{x}$ & \\
\hline Latha & Engineering & $\mathrm{x}$ & & \\
\hline Leon & Computer Science & & $\mathrm{x}$ & \\
\hline Liza & Marketing & & $\mathrm{x}$ & \\
\hline $\mathrm{Su}$ & Literature & & $\mathrm{x}$ & \\
\hline Tom & Education & $\mathrm{x}$ & & \\
\hline
\end{tabular}

successful researchers and witnessed new research active colleagues being recruited. All staff still had some choice in whether to become new or more active researchers and for novices, this required studying for a $\mathrm{PhD}$. A comment was made by Leon about teachers in the latter stages of their career where starting a PhD made little sense: '..because they have been here for so many years.'

Those interviewed had accepted the institution was shifting to university status and that research was now going to be an important part of practice. They recognised individual responsibility in this shift but also that their institution needed to foster a research culture and provide more access to the necessary resources. Nine out of the 18 participants had enrolled in a $\mathrm{PhD}$ programme (seven already had PhDs) and two were considering this action (Table 1). Most in the studying group said that the reason they had decided to do this was because of institutional pressures. Kamila recognised that attaining university status required the institution to have a certain number of PhDs (see Shariffuddin \& Razali, 2017) and both Liza and Su said they were responding to these demands: 'I was told that in order to remain in an academic job, I will need to have a $\mathrm{PhD}$ ' (Su). Kamila explained that: 'when our salary hits the ceiling, in order to get promoted to the next salary scale, it [a $\mathrm{PhD}]$ is a must. In a way, I would say, I have no choice.' Altering promotion and tenure requirements is a recognised strategy that is often used by institutions seeking research productivity (O'Meara, 2007).

In the following sections, we discuss the transition challenges and opportunities experienced by teachers and present two key themes that were present in all 18 interviews. These directly address complex questions about becoming more research active. The first addresses individual motivation and the personal cost to staff and students, and the second what academics had to say about resourcing and support. We conclude by suggesting some necessary changes that can inform institutions and staff undergoing similar transitions.

\section{Intensification of academic work}

It was evident that the burden of responsibility for research productivity sat squarely on the shoulders of academics. Individual teachers needed a clear rationale for effectively changing their jobs and careers. Most seemed to understand the striving ambition of the institution and so their role in research, and for some that was sufficiently motivating, while for others it was not. At this stage in the transition, teachers knew that although they were working towards a research culture, others still had choice in what they did:

People around me don't seem to be motivated about doing research... it is something imposed on them [academic leaders] by the higher management, so they just pass it down to us... The Chinese have this saying, you push them a little bit, and they move one step. You don't push, and then really everyone will remain silent and dormant.

(Charice)

When research is a relatively new mission objective, staff have been found to be neither equipped to, nor desirous of pursuing this (Hazelkorn, 2008). The established demarcation between teaching and research had now resulted in academic staff identifying with either one or the other, and at this stage these activities played a competing rather than complementary role (see Macfarlane \& Hughes, 2009).

The intensification of work resulted in staff having to work at night, on weekends and even during the holidays, and two participants reported doing research during semester breaks. Julie noted that 'sometimes I come back Saturday, Sunday to do my paper... The writing happens outside my normal work hours.' Laila talked about the difficulty of continuous working: 'With hectic teaching during weekdays, the only time we are free to do research are on weekends... having to work 7-days a week is simply depressing.' All those who took part in the study reported high teaching loads throughout the academic year as well as administrative duties, marketing initiatives and studentrelated extra-curricular activities. In the past, research was a permitted activity but was neither required nor officially 
allocated time in the workload model. Therefore, research was a task added to an already full workload and this situation has been reported elsewhere (O'Byrne, 2011). 'I have sacrificed multiple weekends on meeting with other researchers. Often times these meetings would last until midnight. ...What's worse, I had a morning class on that very day' (Ivan).

As a result of this intensification, the work-life balance of participants was negatively affected and finding a balance between work and personal commitments was challenging. To mitigate the pressures, participants adopted various time- and stress-management strategies, while others disengaged from certain areas of their personal and professional lives. Kiki managed her stress through daily meditation and Kamila, who was studying for her $\mathrm{PhD}$, talked about how she tried to manage her emotions by making changes to other aspects of her life:

I have become more prayerful. I've become more religious... I've changed my diet because sometimes my emotions are influenced by my diet. ... And I try to make myself happy and cheerful. ... I take my old clothes and mix and match them, just to make myself feel 'hmm I look good!' Just to boost up my emotions.

Two participants sought time-management tools and techniques: Su used a journal which had a monthly and weekly planner, along with a habit tracker. Kamini used a timemanagement matrix:

Improving time management skills by prioritising and trying my level best to spend most of my time in Quadrant 2 [focus on important but not urgent tasks] of Covey's 4 Quadrants of Time Management Matrix.

Participants' accounts of having to balance work-life commitments echo some of the findings for early career academics in New Zealand universities (Sutherland et al., 2013) and in one sense, this is exactly what respondents had returned to being. However, work-life imbalance caused some to disengage from certain tasks. Disengagement was seen in areas relating to administrative positions and duties, extracurricular student activities, family commitments and social activities, as well as teaching quality. There were numerous illustrations of how administrative duties were set aside but also certain teaching commitments were no longer met. Latha recalled how she did not put her usual effort into teaching when she was busy with her PhD research: '... when I was doing my PhD my teaching quality suffered a bit. Because I didn't have enough time to really fine tune my materials and also the method of delivery.' The experiences of these academics clearly reinforced the idea that research was prioritised over teaching and administration. A similar situation has been observed among research active lecturers in teaching-focused institutions in Ireland (O'Byrne, 2011) and China (Tian \& Lu, 2017); research assumed a higher priority over other activities.

In addition to disengagement from certain work activities, there were accounts of the impact on personal commitments and social activities. Participants reported spending less time with family and friends, and missing out on important family functions. $\mathrm{KiKi}$, who had a young child, lamented that:

My daughter always complains. She said 'Ma, you don't want to spend time with us.' When they wanted to go for a movie, I said 'No, I cannot, you just carry on and follow your father.'

Laila said her research had meant having to withdraw from other aspects of family life:

[I have] sacrificed the time I have with my family. I have worked almost on every weekend for two years... I have missed a lot of family events and compromised on my own marriage. ...working 7-days a week is not an accomplishment or a smart solution, it is the last and only resort. ... No researcher can work 7-days forever, it has been two years for me and I am at the edge of collapsing.

Laila, recognised that her work regime was unsustainable. However, research productivity is likely to require more time at work (Kwiek, 2016, 2018) and Boyd and Smith (2016) found academics experiencing burnout and changes in their home and family life. Murray (2013) contends that because the act of writing is neither defined nor accounted in workload models, academics consequently struggle with disengagement-engagement tensions:

It seems absurd to be calling for institutions to make writing more central to academic work when it is already so important, but it is equally absurd to allocate a key academic activity to personal time, as if it were, indeed, a hobby. (p. 90)

In the present study, participants showed some agency and were not entirely passive to external demands, but they also spoke of the personal cost of focusing on research.

\section{Resources and support}

Building institutional research capacity requires systematic support from both management and academics (Bai et al., 2013). However, the data clearly showed that the intensified working environment came about mainly because no new time was allocated for research and nearly everything had to be accomplished on top of a normal workload, including studying for a $\mathrm{PhD}$. There was a small amount of give and take and research appeared to be a leverage tool in negotiation with managers. For example, Charice was able to set aside work hours to conduct research interviews, and also 
requested not to be assigned to teach a particular subject that required a lot of planning and preparation. However, not everyone was supported in this way and the institution could not afford to reduce teaching loads at the obvious risk of losing fee-paying students. This difficult situation seemed to have been recognised and accepted by both management and staff, and as a consequence both parties sought other solutions to support the transition to becoming research active. Three areas were mentioned by respondents. These were access to journals, research mentors and encouraging collaboration to create a research environment and enhance research capacity.

Four participants wished to receive financial rewards for publications, which is done in some Malaysian institution, and further ten participants sought access to a broader collection of indexed journals, conference funding and ICT tools. Poor access to journals slowed down research because:

A lot of time is wasted just browsing through and trying to get the full text access from the authors... You know, going on a merry-go-round, just trying to get articles.

\section{(Charice)}

Jennie suggested that it was like going 'through a rainforest' to look for resources. Yet it was not just lack of journals but also appropriate software which two respondents had paid for themselves. More importantly, for these relatively new researchers there was no genuine research environment and participants looked to mentors and research-partners to provide guidance and a new work culture. They felt various emotions, including: 'throwing us into the deep end' (Harvey), 'blind leading the blind' (Ivan), 'groping around, not knowing what to do' (Charice), 'need some kind of master research figure' (Fay) and, 'we have been pressured to produce research but without much guidance and experience. So frankly speaking, I am lost' (Amy).

Collaborative strategies within and outside the institution were encouraged and adopted and research has shown that those who collaborate both at a domestic and international level can obtain greater access to resources, enhance research skills and become more effective writers (Kuzhabekova \& Mukhamejanova, 2017; Nguyen \& Klopper, 2014; Nygaard, 2017). Examples from the present study included formal and informal peer research groups.

One faculty 'manufactured' research teams and compelled some staff to join them. These teams were given a list of research activities to complete within a timeframe of one year, with the end goal being a publication in a highranked journal. This initiative was received with mixed feelings by all those involved. For six participants it motivated them but others said that the expectation to publish within a timeframe of one year was restrictive and ineffective. These staff felt that they lacked experience in writing for publication and needed stronger guidance and mentorship to do this. Although more than a year had passed since these research teams had been initiated, none of the participants involved had managed to publish. In part this was attributed to a lack of skills and research culture. Hayati shares the experience of her research group which failed through lack of guidance:

We were not very successful in the first attempt to work in a team due to the lack of vision and direction. Therefore, I am afraid there was no research engagement. There was no other attempt to get back into a research group... I think we had different commitments and priorities. It could be from the lack of time for research itself.

(Hayati).

The institution did organise separate research training and seven respondents had attended researcher development courses and workshops. Some also mentioned paying the attendance fees to join workshops that were organised by external parties.

In addition to connecting and collaborating within the institution, six participants worked with and sought guidance from former and current $\mathrm{PhD}$ supervisors from outside. Latha published with her former supervisor and Julie, whose supervisor was from a public research university gained access to new funding:

We went to this conference where they said we can publish in SCOPUS ... So, this is how me and my [former] supervisor collaborate. She sponsors, because she has [a] grant. I don't have [a] grant. So, we collaborate in terms of I am writing, and she is doing the presentation, paying the fee and so on.

Julie recognised that connections play an important role and described why she found it necessary to continue working with her former supervisor:

We cannot do solo actually. For me, I collaborate with [a] government university, and I can see it has a little bit of impact. But it's okay for me. I want to accumulate it. In Chinese we say 'use a small knife to cut a big tree.' But slowly we will get to cut it. It's a very slow progress, but we are doing it. I'm not using a big saw.

While the full effects of collaborations with experienced researchers from the broader sector are not yet fully known, there was a positive impact on research and in some instances it resulted in getting research published. Working with others was also seen as important in this study as networking and linkages are criteria in the Malaysian Research Assessment (MyRA) exercise. 


\section{Conclusions}

Aspiring to become a university and, in the longer term, an improved position in local and international league tables was seen as positive in different ways. Malaysian society, the institution, its academic staff and students were all seen to benefit. Advantages included improving the institution's commercial standing alongside status gains, as well as academics being able to contribute more to the global knowledge project through their research and development. In addition, the advanced practise of teaching postgraduates required more staff to gain a $\mathrm{PhD}$, and doctoral education was also viewed as a key component of higher education's research project and something that would bring economic returns to the institution and society. Overall, the drivers for becoming a university and developing research were mainly economic or related to status. What was not mentioned was the logic of improving teaching quality in a new research-oriented institution. The Humboldtian connection between research and teaching (Brew, 2010; Harland, 2016) seemed lost among other arguments and drivers of change. However, in the long run, it can be argued that student education will improve as a result of the organisation becoming a research-led.

In order to meet its aspirations, this striving institution needed clarity of vision and a strong drive, but these aspirations meant very little in comparison to asking staff to upskill to what is effectively a new career without appropriate support. Pressures for change came from various quarters (Fig. 1) and yet global, national and institutional imperatives appeared to have coalesced to create extremely unhealthy pressures on the academics who took part in this study. All had accepted the change, either willingly or under duress; however, turning teachers into academics takes time and resources and the accelerated pace of change left the burden squarely on the shoulders of an academic workforce that did not feel supported. Both the teaching academics studying for a $\mathrm{PhD}$ and those with their doctorates needed time and space in which to upskill so that there was less personal cost to the individual. However, we are aware that there may also be a large gap between being awarded a PhD and regular independent publishing. Of course management would be well-aware of these circumstances and challenges. The required skills cannot be manufactured quickly but the institution needed to meet its agenda for reform while making sure the business did not suffer. The logical strategy would be to invest in new teachers and allocate lighter teaching loads to those academics making the transition to research. However, it is hard to envisage such massive investment and so the institution must look to other ways to resolve this catch22 situation.
Such conditions for change may reflect some of the difficulties faced in the Global South; however, it is likely that similar stories are to be found across different higher education sectors faced with similar challenges. Appropriate support is crucial in such situations, especially with respect to time and setting reasonable goals that do not intensify academic work to such a degree. The doctorate is a first step for many but even this may not lead to being a productive researcher (Sinclair et al., 2014). What is needed is for teachers to be genuinely motivated to take on the new vision, and then for an institutional culture of patience that sits alongside the opportunities of rewards for success. In the longer-term this will necessitate changes to recruitment but more will be needed to ensure research excellence and highquality teaching. If these are the aspirational characteristics to be found in the ancient and older universities of the world, then how can a new institution aspire to these attributes in a reasonable and humane manner?

\section{References}

Altbach, P. G. (2009). Peripheries and centers: research universities in developing countries. Asia Pacific Education Review, 10(1), 15-27. https://doi.org/10.1007/s12564-009-9000-9.

Bai, L., Millwater, J., \& Hudson, P. (2013). Factors that influence Chinese TEFL academics' research capacity building: an institutional case study. Asia-Pacific Education Researcher, 22(2), 119-126. https://doi.org/10.1007/s40299-012-0004-6.

Boliver, V. (2015). Are there distinctive clusters of higher and lower status universities in the UK? Oxford Review of Education, 41(5), 608-627.

Boyd, P., \& Smith, C. (2016). The contemporary academic: orientation towards research work and researcher identity of higher education lecturers in the health professions. Studies in Higher Education, 41(4), 678-695. https://doi.org/10.1080/03075079.2014.943657.

Brew, A. (2010). Imperatives and challenges in integrating teaching and research. Higher Education Research \& Development, 29(2), 139-150.

Dugas, D., Stich, A. E., Harris, L. N., \& Summers, K. H. (2020). 'I'm being pulled in too many different directions': Academic identity tensions at regional public universities in challenging economic times. Studies in Higher Education, 45(2), 312-326.

Garratt, D., \& Hammersley-Fletcher, L. (2009). Academic Iientities in flux: Ambivalent articulations in a post-1992 university. Power and Education, 1(3), 307-318.

Gonzales, L. D. (2015). Faculty agency in striving university contexts: Mundane yet powerful acts of agency. British Educational Research Journal, 41(2), 303-323.

Gonzales, L. D., Martinez, E., \& Ordu, C. (2014). Exploring faculty experiences in a striving university through the lens of academic capitalism. Studies in Higher Education, 39(7), 1097-1115.

Harland, T. (2016). Teaching to enhance research. Higher Education Research \& Development, 35(3), 461-472.

Hazelkorn, E. (2005). University Research Management: Developing Research in New Institutions. . OECD Publishing.

Hazelkorn, E. (2008). Motivating Individuals: Growing research from a "fragile base." Tertiary Education and Management, 14(2), $151-171$. 
Hazelkorn, E. (2015). Rankings and the Reshaping of Higher Education: The Battle for World-Class Excellence. (2nd ed.). Palgrave Macmillan.

Hazelkorn, E., \& Moynihan, A. (2010). Transforming academic practice: Human resource challenges. In S. Kyvik \& B. Lepori (Eds.), The Research Mission of Higher Education Institutions outside the University Sector: Striving for Differentiation. (pp. 77-93). Springer.

Kuzhabekova, A., \& Mukhamejanova, D. (2017). Productive researchers in countries with limited research capacity: researchers as agents in post-Soviet Kazakhstan. Studies in Graduate and Postdoctoral Education, 8(1), 1-17. https://doi.org/10.1108/ SGPE-08-2016-0018.

Kwiek, M. (2016). The European research elite: a cross-national study of highly productive academics in 11 countries. Higher Education, 71(3), 379-397. https://doi.org/10.1007/s10734-015-9910-x.

Kwiek, M. (2018). High research productivity in vertically undifferentiated higher education systems: Who are the top performers? Scientometrics, 115(1), 415-462. https://doi.org/10.1007/ s11192-018-2644-7.

Kyvik, S., \& Lepori, B. (2010). Research in higher education institutions outside the university sector. In S. Kyvik \& B. Lepori (Eds.), The Research Mission of Higher Education Institutions outside the University Sector: Striving for Differentiation. (pp. 3-21). Springer.

Macfarlane, B., \& Hughes, G. (2009). Turning teachers into academics? The role of educational development in fostering synergy between teaching and research. Innovations in Education and Teaching International, 46(1), 5-14.

Martinez, E. (2019). "The rules change": Exploring faculty experiences and work expectations within a drifting community college context. Community College Review, 47(2), 111-135.

Ministry of Education Malaysia. (2015). The Malaysia Education Blueprint 2015-2025 (Higher Education). . Kementerian Pendidikan Malaysia.

Murray, R. (2013). "It's not a hobby": reconceptualizing the place of writing in academic work. Higher Education, 66(1), 79-91. https://doi.org/10.1007/s10734-012-9591-7.

Nerad, M., Trzyna, T., \& Heggelund, M. (2008). Introduction. In M. Nerad \& M. Heggelund (Eds.), Toward a Global PhD?: Forces and Forms in Doctoral Education Worldwide. (pp. 3-16). University of Washington Press.

Nguyen, Q., \& Klopper, Christopher. (2014). The influences of research environment within a university on research productivity of academic staff - a case study in a research oriented university in Vietnam. International Journal of Arts \& Sciences, 07(02), 189-197.

Nygaard, L. P. (2017). Publishing and perishing: an academic literacies framework for investigating research productivity. Studies in Higher Education, 42(3), 519-532. https://doi.org/10.1080/03075 079.2015.1058351.
O'Byrne, C. (2011). Against the odds: researcher development in teaching-focused HEIs. International Journal for Researcher Development, 2(1), 8-25. https://doi.org/10.1108/17597511111177998.

O'Meara, K. (2007). Striving for what? Exploring the pursuit of prestige. In J. C. Smart (Ed.), Higher Education: Handbook of Theory and Research (Volume 22). (pp. 121-179). Springer.

O'Meara, K., \& Bloomgarden, A. (2011). The pursuit of prestige: The experience of institutional striving from a faculty perspective. Journal of the Professoriate, 4(1), 39-73.

Pusser, B., \& Marginson, S. (2013). University rankings in critical perspective. The Journal of Higher Education, 84(4), 544-568.

Shariffuddin, S. A., \& Razali, J. R. (2017). Transformation of university colleges to full-pledged universities: A proposed conceptual framework for Malaysian higher learning institutions. International Journal of Advanced and Applied Sciences, 4(12), 2017.

Sinclair, J., Barnacle, R., \& Cuthbert, D. (2014). How the doctorate contributes to the formation of active researchers: What the research tells us. Studies in Higher Education, 39(10), 1972-1986.

Stensaker, B., Lee, J. J., Rhoades, G., Ghosh, S., Castiello-Gutiérrez, S., Vance, H., et al. (2019). Stratified university strategies: The shaping of institutional legitimacy in a global perspective. The Journal of Higher Education, 90(4), 539-562. https://doi.org/10. 1080/00221546.2018.1513306.

Sutherland, K., Wilson, M., \& Williams, P. (2013). Success in academia? The experiences of early career academics in New Zealand universities. Wellington. Retrieved from https://akoaotearoa.ac.nz/ download/ng/file/group-5314/report-success-in-academia-suthe rland.pdf

Tham, S. Y. (2013). Internationalizing higher education in Malaysia: Government policies and university's response. Journal of Studies in International Education, 17(5), 648-662.

Thomas, D. (2006). A general inductive approach for analyzing qualitative evaluation data. American Journal of Evaluation, 27(2), 237-246. https://doi.org/10.1177/1098214005283748.

Tian, M., \& Lu, G. (2017). What price the building of world-class universities? Academic pressure faced by young lecturers at a research-centered University in China. Teaching in Higher Education, 22(8), 957-974. https://doi.org/10.1080/13562517.2017. 1319814.

van Winkel, M. A., van der Rijst, R. M., Poell, R. F., \& van Driel, J. H. (2018). Identities of research-active academics in new universities: Towards a complete academic profession cross-cutting different worlds of practice. Journal of Further and Higher Education, 42(4), 539-555.

Publisher's Note Springer Nature remains neutral with regard to jurisdictional claims in published maps and institutional affiliations. 